\title{
A Novel Method for Isolating Pure Microvascular Endothelial Cells from Subcutaneous Fat Tissue Ideal for Direct Cell Seeding
}

\author{
Cora H. P. Arts, Glenda J. Heijnen-Snyder, Paul Ph. A. Hedeman Joosten, \\ Hence J. M. Verhagen, Bert C. Eikelboom, Jan J. Sixma, and Philip G. de Groot \\ Thrombosis and Hemostasis Laboratory, Department of Hematology (CHPA, GJH-S, JJS, PGG) and Department of \\ Vascular and Transplantation Surgery (CHPA, GJH-S, PPAHJ, HJMV, BCE), University Medical Center, Utrecht, \\ The Netherlands
}

$E$ ndothelial cell (EC) seeding improves the patency of small-diameter vascular grafts (Zilla et al, 1993). Subcutaneous fat is an attractive source for large amounts of microvascular EC (MVEC) (Williams et al, 1986), circumventing the need for additional cell culturing. Together with human MVEC, however, (myo)fibroblast-like cells or pericytes and macrophages are isolated (Meerbaum et al, 1992; Rubens et al, 1997). We established that $39 \pm 3 \%$ (mean \pm SEM, $n=6$ ) of fat-derived cells are EC (Fig. 1A), about $2 \%$ macrophages, and all others fibroblast-like cells. Here, we have introduced an additional purification step to deplete fat-derived MVEC of the contaminants. Immediately after the traditional isolation procedure, a combination of Dynabeads coated with fibroblast- and macrophage-specific antibodies is added. The purity is increased to $91 \pm 1 \%$ (mean \pm SEM, $n=6$ ) (Fig. 1B).

M450 G $\alpha$ M Dynabeads (Dynal AS, Oslo, Norway) were washed twice with sterile PBS/0.1\% BSA (Sigma-Aldrich Chemie, Steinheim, Germany). Beads were coated with mouse monoclonal antibody $11 \mathrm{FI}-$ BRAU (F11) (Imgen, ITK Diagnostics, Uithoorn, the Netherlands/Serotec, Oxford, United Kingdom) (Fearns and Dowdle, 1992), $1.5 \mu \mathrm{g} / 10^{7}$ beads in $100 \mu \mathrm{l}$ PBS/BSA, and with mouse monoclonal antibody against CD14 (DAKO, Glostrup, Denmark), $0.25 \mu \mathrm{g} /$ $10^{7}$ beads in $100 \mu \mathrm{l} \mathrm{PBS} / \mathrm{BSA}$, for 30 minutes at $4^{\circ} \mathrm{C}$ on a roller bank, followed by four wash steps.

The specificity of F11 to bind fibroblast-like cells and not MVEC was shown with immunohistochemistry of frozen sections of subcutaneous fat tissue and with flow cytometry of nonpurified cells double-stained with F11 and CD31, an EC marker. The cell-specific

Received June 21, 2001.

This study was supported by Grant 97.165 of the Netherlands Heart Foundation.

Address reprint requests to: Dr. Cora H. P. Arts, Department of Surgery, University Medical Center Utrecht, P.O. Box 85500, G 04.228, 3508 GA Utrecht, The Netherlands.E-mail:c.h.p.arts@chir.azu.nl binding capacity of the F11-coated beads was established with cultured lung fibroblasts, and the CD14coated beads were tested with freshly isolated monocytes. Our procedure was first tested on a mixture of cultured cells: $65 \%$ fibroblasts, $30 \%$ human umbilical vein EC (HUVEC), and 5\% monocytes.

Liposuction fat, obtained after informed consent, was centrifuged (3000 rpm; 15 minutes) to remove the liposuction fluid. Amounts of fat were mixed with equal volumes of crude collagenase from Clostridium histolyticum (Sigma-Aldrich Chemie) $(0.4 \%$ w/v)/BSA $(0.4 \% \mathrm{w} / \mathrm{v})$ in PBS, pH 7.4 (Williams et al, 1986). After incubation for 30 minutes at $37^{\circ} \mathrm{C}$ under continuous vigorous shaking, the digested fat was centrifuged (1200 rpm, 12 minutes, room temperature [RT]). The pellets were then resuspended in Medium 199 (Gibco; Invitrogen, Carlsbad, California). The cell suspension was centrifuged again (1100 rpm, 5 minutes, RT), and the pellets were resuspended in RPMI/1\% fetal bovine serum (FBS). The cell suspension was sieved (pore size: $0.6-0.7 \mathrm{~mm}$ ) and the cells were counted.

Cells, $2 \times 10^{6} / \mathrm{mL}$, were added to $10^{7}$ F11-beads and $1.25 \times 10^{6}$ CD14-beads, and incubations were performed for 20 minutes at $4^{\circ} \mathrm{C}$ on a rollerbank. "Bound" and "nonbound" cells were separated with a Magnetic Particle Concentrator (MPC) (Dynal). Bound cells were resuspended in RPMI/1\% FBS, and cells were separated for a second time. Supernatants with nonbound cells were transferred to clean tubes and the separation was repeated to remove any remaining beads. Bound and nonbound cells were collected in EBM-MV2 Bulletkit culture median (Clonetics, BioWhittaker, Verviers, Belgium) with $0.5 \mu \mathrm{M}$ cAMP (Sigma) (Davison and Karasek, 1981). Nonpurified, purified (nonbound), and removed (bound) cells were seeded $\left(10^{5} / \mathrm{cm}^{2}\right)$ on human fibronectin-coated culture plates.

The identity of the isolated cells was established with immunocytochemistry and flow cytometry, using FITC-conjugated mouse anti-human CD31 (Pharmingen, Leiden, The Netherlands), mouse anti-human CD31 (DAKO), EN4 (Monosan; Sanbio, Uden, the 


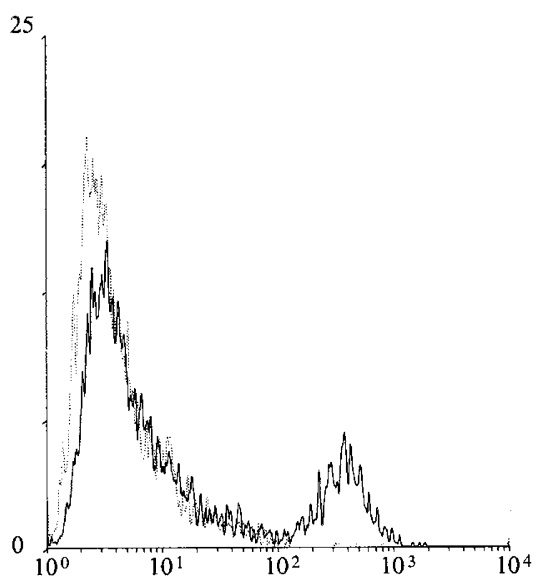

A

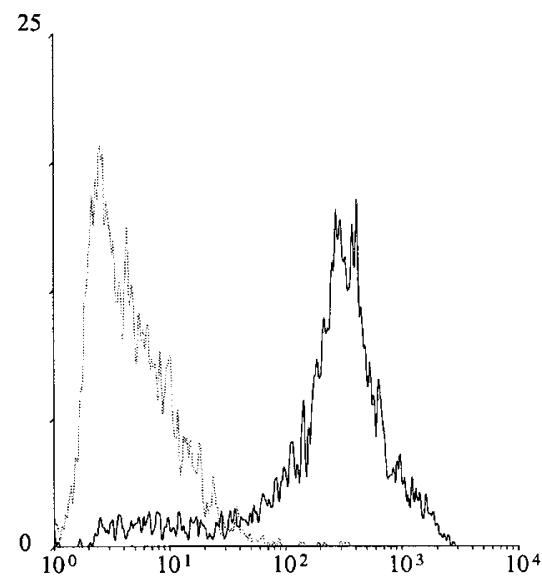

B

Figure 1.

Flow cytometry of nonpurified and purified cells. Cells were stained with the mouse anti-human EN4. Fluorescence of stained cells (black line) was compared with that of control cells, only exposed to the second antibody (FITC-conjugated goat anti-mouse) (gray line). A, Nonpurified cells. B, Purified cells.

Netherlands), von Willebrand factor (vWF, DAKO), CD14, $\alpha$-actin (DAKO), vimentin (DAKO), F11, intercellular adhesion molecule (ICAM, DAKO) (after TNF $\alpha$ stimulation) and, for visualization, FITC-conjugated (Becton Dickinson, Bedford, Massachusetts) and PEconjugated (Southern Biotechnologies, Birmingham, Alabama) goat anti-mouse. Nuclei were stained with propidium iodide (Sigma-Aldrich Chemie).

The yield of the depletion method was compared with that of three positive selection methods, using the EC-specific antibody EN4, the antibody against CD31 and lectin Ulex europaeus-1 (UEA-1) (Sigma-Aldrich Chemie), $1.5 \mu \mathrm{g}$ of both antibodies, and $0.5 \mathrm{mg}$ UEA-1 per $10^{7}$ beads (Jackson et al, 1990; Rubens et al, 1997). Nonpurified cells, $2 \times 10^{6}$ in $400 \mu \mathrm{l}$, were added to $4 \times 10^{6}$ EN4-, CD31-, and UEA-1-beads. The cell-specific binding capacity was determined with HUVEC.

The F11-antibody did not recognize MVEC as shown by immunohistochemistry $(n=3)$ (Fig. 2A) and flow cytometry $(n=3)$ (Fig. 2B). The cell-specific binding capacities of the F11- and CD14-coated beads were $94 \pm 0 \%$ and $98 \pm 3 \%$, respectively (mean $\pm \mathrm{SEM}, n=3$ ). After using our purification method on a combination of HUVEC, fibroblasts, and monocytes, $93 \pm 4 \%$ of the depleted cells and $1.7 \pm$ $0.9 \%$ of the removed cells were HUVEC (mean \pm SEM, $n=3$ ).

The average yield of purified cells obtained with our depletion method was $3.2 \pm 0.2 \times 10^{5}$ cells $/ g$ (33 \pm $2 \%$ of the nonpurified cells) (mean \pm SEM, $n=6$ ). The amount of EC in the purified population was $91 \pm 1 \%$, as determined by CD31- or EN4-expression (mean \pm SEM, $n=6$ ) (Figs. 1B and 3A). EC also expressed ICAM and vWF (Fig. 3B). Approximately $7 \%$ of the purified cells showed a positive reaction with $\mathrm{F} 11$, and none with the marker against CD14. Of the removed cells, approximately $3 \%$ were macrophages, $11 \pm 2 \%$ (mean \pm SEM, $n=6$ ) MVEC, and all the rest fibro- blasts (Fig. 3C). All purified and removed cells showed a slightly positive reaction with the mesenchymal precursor marker vimentin, and none with the smooth muscle marker against $\alpha$-actin. The isolation time increased from $110.5 \pm 1.5$ minutes to $154 \pm 2.5$ minutes (mean \pm SEM, $n=3$ ).

The cell-specific binding capacities of the EN4-, CD31-, and UEA-1-beads, were $95 \pm 2 \%, 52 \pm 21 \%$, and $93 \% \pm 2 \%$, respectively (mean \pm SEM, $n=3$ ). The yields of the positive selection methods were $74 \pm$ $15 \%, 14 \pm 3 \%(p<0.05)$, and 37\% $\pm 9 \%(p<0.05)$, respectively, of the yield obtained with the depletion method (mean \pm SEM, $n=3$ ).

Positive selection-specific problems are avoided with our depletion method, an excess of beads can be added without harming the target cells, and beads do not need to be removed (Jackson et al, 1990). An explanation for the smaller yield obtained with positive selection might be the loss of EC-specific antigens from the surface because of enzymatic digestion (Rubens et al, 1997).

In this study we have introduced a novel method for purifying fat-derived MVEC using a combination of Dynabeads directed against fibroblasts and macrophages. The purity is increased from $40 \%$ to over $90 \%$. The yield is larger than after positive selection. Cells are free of beads and can be immediately used for cell seeding.

\section{Acknowledgements}

We thank J. Scharringa and N. M. de Vos, Department of Microbiology and Virology, University Medical Center Utrecht, The Netherlands, for providing the freshly isolated monocytes and the Department of Plastic Surgery, University Medical Center Utrecht and Medical Esthetical Center Bartelski, Bosch en Duin, The Netherlands for their help in supplying us with liposuction fat. 

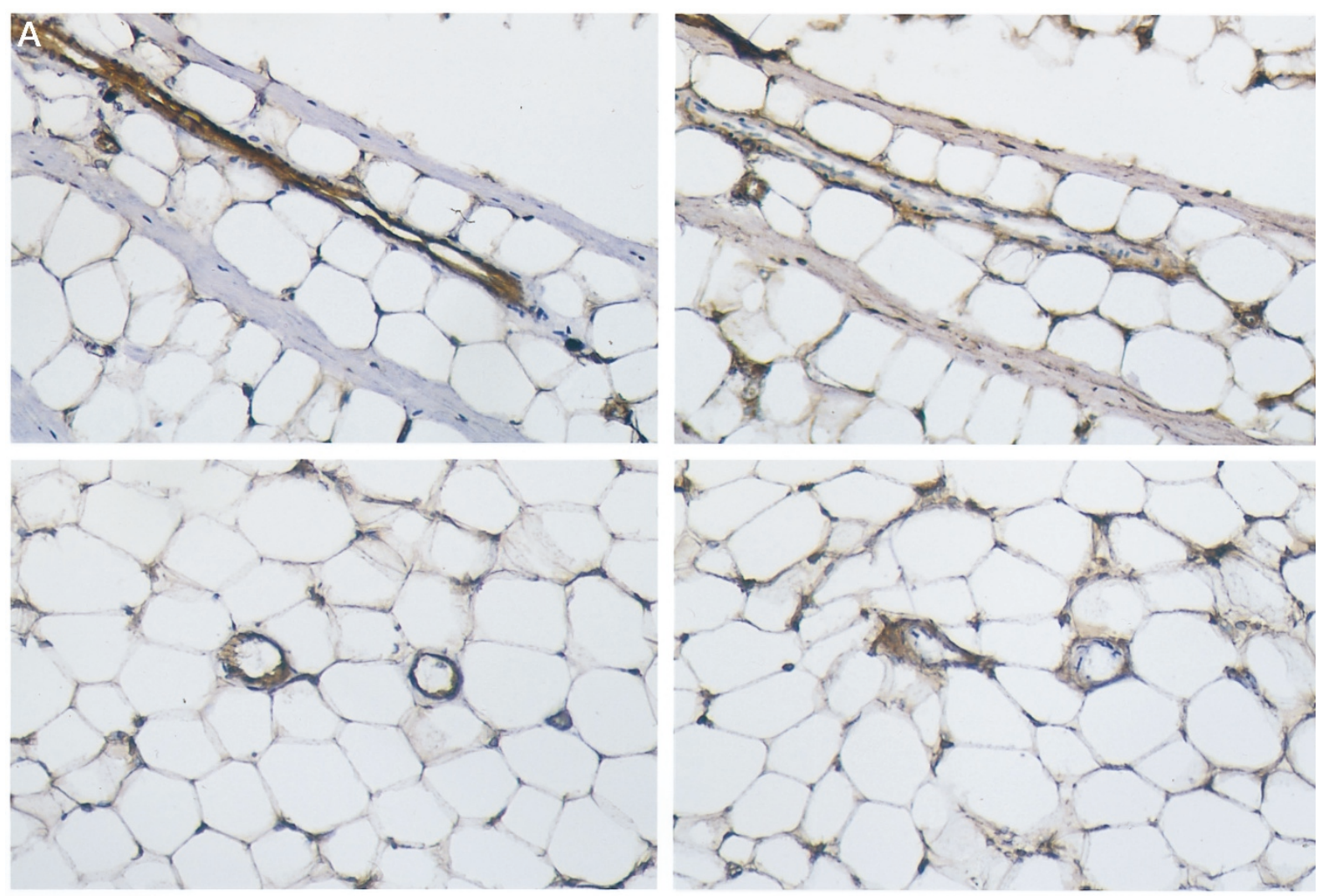

\section{B}

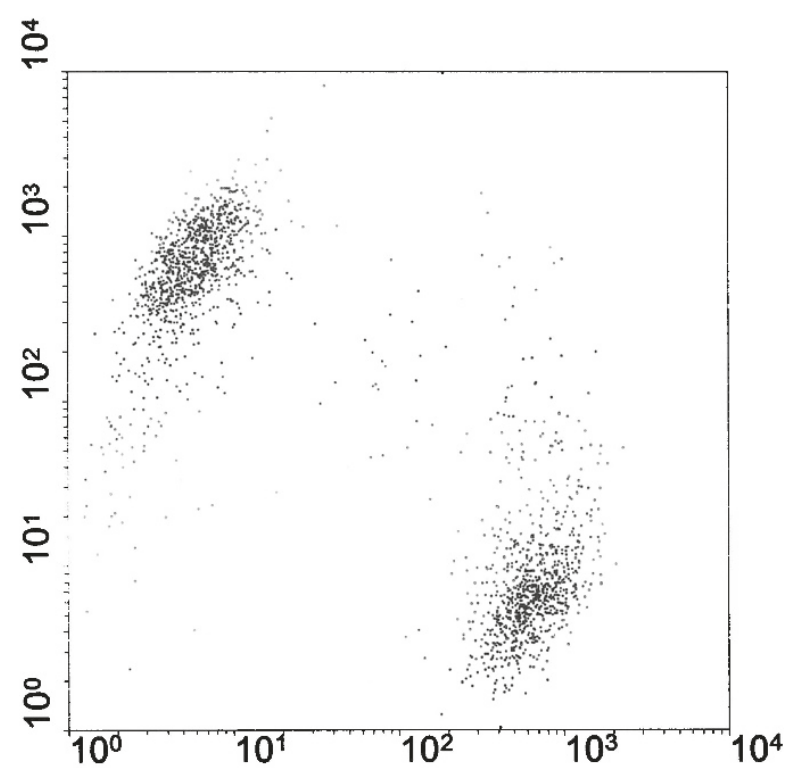

Figure 2.

A, Immunohistochemistry of frozen sections of subcutaneous fat tissue. On the left, two sections stained with mouse anti-human CD31; on the right, two identical sections stained with mouse anti-human F11 (magnification, $\times 108$ ). B, Flow cytometry analysis of nonpurified cells. Cells were double-stained with FITC-conjugated mouse anti-human CD31 (horizontal axis) and with mouse anti-human F11, visualized with PE-conjugated goat anti-mouse (vertical axis). 

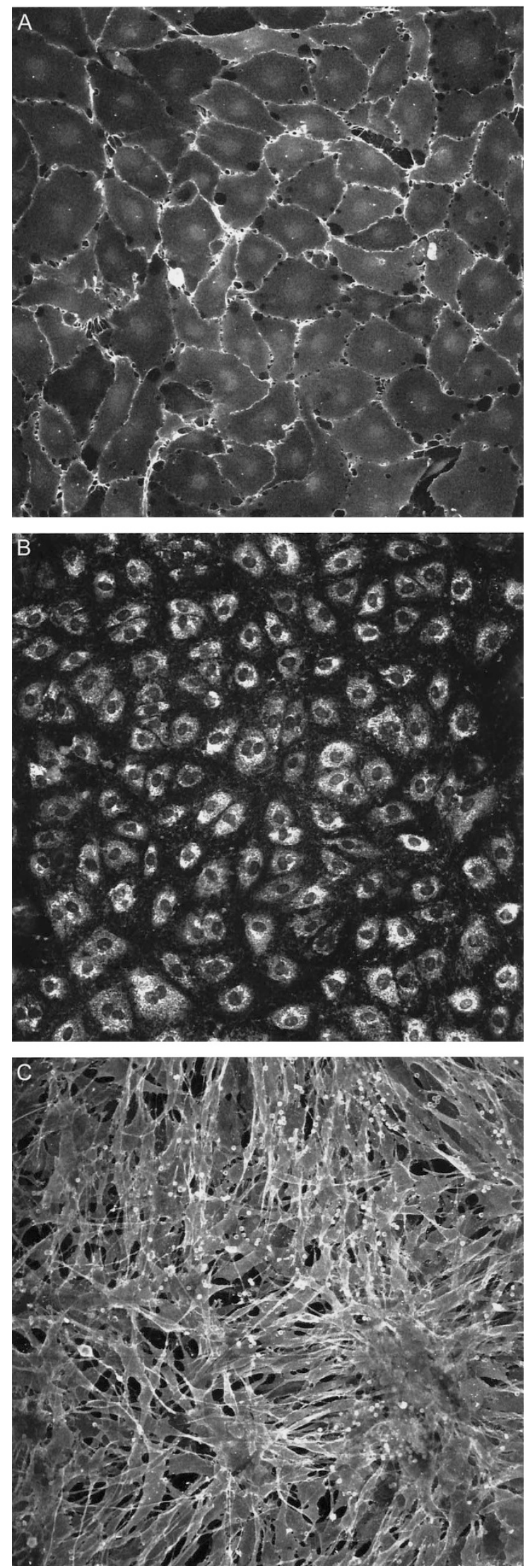

Figure 3.

Immunocytochemistry of purified cells and removed cells. A, Purified cells, positive for the endothelial cell (EC) marker against CD31 (magnification, $\times 130$ ). B, Purified cells, positive for the EC marker against von Willebrand factor (VWF) (magnification, $\times 130$ ). C, Removed cells, positive for the fibroblast marker F11 (magnification, $\times 130$ ). 


\section{References}

Davison PM and Karasek MA (1981). Human dermal microvascular endothelial cells in vitro: Effect of cyclic AMP on cellular morphology and proliferation rate. J Cell Physiol 106:253-258.

Fearns C and Dowdle EB (1992). The desmoplastic response: Induction of collagen synthesis by melanoma cells in vitro. Int J Cancer 50:621-627.

Jackson CJ, Garbett PK, Nissen B, and Schrieber L (1990). Binding of human endothelium to Ulex europaeus I-coated Dynabeads: Application to the isolation of microvascular endothelium. J Cell Sci 96:257-262.

Meerbaum SO, Sharp WV, and Schmidt SP (1992). Lower extremity revascularisation with polytetrafluoroethylene grafts seeded with microvascular endothelial cells. In: Zilla P, Fasol R, and Callow A, editors. Applied Cardiovascular Biology, 1990-1991. International Society for Applied Cardiovascular Biology. Vienna: Karger-Basel, 107-119.
Rubens FD, Labow RS, Meek E, Dudani AK, and Ganz PR (1997). Tissue factor expression by cells used for sodding of prosthetic vascular grafts. J Surg Res 72:22-28.

Williams SK, Jarrell BE, and Rose DG (1986). Isolation of human fat-derived microvascular endothelial cells for use in vascular graft endothelialization. In: Zilla $\mathrm{P}$, Fasol $\mathrm{R}$, and Deutsch M, editors. Endothelialization of Vascular Grafts. First European Workshop on Advanced Technologies in Vascular Surgery. Vienna: Karger-Basel, 211-217.

Zilla P, von Oppell U, and Deutsch M (1993). The endothelium: A key to the future. J Card Surg 8:32-60. 